\title{
Study the Effects of Dopamine on Oliguric Patients Referred to Amir Kabir Pediatrics Hospital of Arak University of Medical Sciences, Iran
}

\section{7 - 2018}

\author{
Vahab Ghanbari Sheldareh ${ }^{1,{ }^{*}}$, Parsa Yousefichaijan ${ }^{2}$, Yazdan Ghandi ${ }^{3}$ and Danial Habibi ${ }^{4}$ \\ ${ }^{1}$ Department of Pediatrics, Faculty of Medicine, Arak University of Medical Sciences, Arak, Iran \\ ${ }^{2}$ Department of Pediatrics, Pediatric Nephrology, Faculty of Medicine, Arak University of Medical Sciences, Arak, Iran \\ ${ }^{3}$ Department of Pediatrics, Pediatric Cardiology, Arak University of Medical Sciences, Arak, Iran \\ ${ }^{4}$ Department of Biostatistics, Faculty of Medicine, Arak University of Medical Sciences, Arak, Iran \\ "Corresponding author: Department of Pediatrics, Amirkabir Hospital, Faculty of Medicine, Arak University of Medical Sciences, Arak, Iran. Tel: +98-9144352767. Email: \\ vgirsh66@yahoo.com
}

Received 2018 November 14; Accepted 2018 November 24.

\begin{abstract}
Acute kidney injury (AKI) or acute renal failure is a clinical manifestation in which the kidneys are unable to preserve the normal homeostasis of water and electrolytes. To evaluate the effects of low dose dopamine to improve the renal functions in children, 3 $\mu \mathrm{g} / \mathrm{kg} / \mathrm{min}$, IV infusion of dopamine was prescribed. The results of this study showed that low dose dopamine improved the serum creatinine concentration and corrected the time of appropriate urine volume, however, it was not effective on the serum electrolytes ( $\mathrm{Na}, \mathrm{K}, \mathrm{Bicarbonates,} \mathrm{BUN}$ ) and the glomerular filtration rate (GFR).
\end{abstract}

Keywords: Dopamine, Oliguric Patients, Oliguria

\section{Background}

Acute kidney injury (Acute renal failure) is a clinical manifestation in which the kidneys are unable to preserve the normal homeostasis of water and electrolytes of the body (1). Acute kidney injury (AKI) is appeared as oliguria, anuria, or may be exhibited with the normal volume of urine. Oliguria, urine excretion less than $400 \mathrm{~mL} /$ day, is the most prevalent sign of acute kidney injury. Anuria, urine excretion less than $50 \mathrm{~mL} /$ day, and AKI with the normal urine output, are not as prevalent as oliguria.

An abbreviation word (RIFLE) is used for pediatric classification of acute kidney injury. R(risk), implies a decrease in renal clearance up to $25 \%$ and urine output less than $0.5 \mathrm{~mL} / \mathrm{kg} / \mathrm{h}$ for eight hours. I (injury), fall in renal clearance up to $50 \%$ and urine output less than $0.5 \mathrm{~mL} / \mathrm{kg} / \mathrm{h}$ for 16 hours. F (failure), 75\% decrease of urine clearance or $35 \mathrm{~mL} / \mathrm{min} / 1.73 \mathrm{~m}^{2}$ of serum clearance and urine output less than $0.3 \mathrm{cc} / \mathrm{kg} / \mathrm{h}$ or being anuria for 12 hours. L (loss), loss of renal function for more than four weeks. Finally, E (end stage), which implies permanent renal failure for more than three months (2).

Acute kidney injury commonly has three pre-renal, renal, and post renal main sources. Pre renal AKI comes from inadequate perfusion of the renal tissues due to renal artery obstruction or stenosis. The renal part of AKI is caused by acute damage or destruction of the renal tissues and the post renal AKI comes from obstruction of ureter or any other parts of urine out flow.

In patients with pre renal azotemia, sodium concentration of urine will be decreased to less than $20 \mathrm{meq} / \mathrm{L}$ while the urine sedimentation remains normal. Other studies showed that fractional excretion of sodium (FE Na) depends on glomerular filtration rate and the amount of sodium intake (3).

Many drugs are used to improve the prognosis of the AKI. Diuretics are commonly prescribed to correct the volume of the body fluid, however, their role in reducing the required time for treating the AKI have not yet been established (4). Low dose dopamine ( $1-3 \mu \mathrm{g} / \mathrm{kg} / \mathrm{min})$, due to its effects on dopaminergic receptors of the kidneys, is usually used to dilate the renal arteries and increase the urine output, whereas high dose dopamine (10 - $20 \mu \mathrm{g} / \mathrm{kg} / \mathrm{min})$, by stimulating $\alpha$ and $\beta$ sympathetic receptors, causes constriction of renal, mesenteric, and peripheral arteries. Increasing the peripheral vascular resistance and cardiac oxygen demand may lead to myocardial ischemia (5).

It is suggested that imbalance renal medullary oxy- 
gen supply/demand relationship can cause ischemic acute kidney injury. Infusion of dopamine at $2-4 \mu \mathrm{g} / \mathrm{kg} / \mathrm{min}$ increases the renal oxygen supply by a pronounced preand post-glomerular vasodilation (6). Infusion of low dose dopamine is normally associated with an increase in creatinine clearance and reduction in erythropoietin (EPO) levels in patients with IgA nephropathy. The patients who showed a fall in EPO had less proteinuria and lower serum uric acid and lower blood pressure (7).

\section{Methods}

This study was carried out as an un-blinded clinical trial at the Arak Amir Kabir Pediatrics Hospital of the Arak University of Medical Sciences, Iran. Among the patients younger than 15 years' old, whom were admitted due to acute kidney injury and had oliguria, 120 subjects have been selected for this study. Previously, the oliguric patients with AKI, who had any other kinds of chronic kidney diseases or malignancy, have been excluded. The selected patients have been randomly divided into two 60 experimental and 60 control groups without considering their gender (Table 1). For each patient of the experimental group, low dose dopamine ( $3 \mu \mathrm{g} / \mathrm{kg} / \mathrm{min}$ ) IV infusion were prescribed and the control group received maintenance serum therapy by infusion of normal saline. The glomerular filtration rate (GFR), serum $\mathrm{Na}, \mathrm{K}, \mathrm{BUN}, \mathrm{Cr}$, and bicarbonate, prior to intervention for the experimental and the control groups, were measured. The serum concentration of $\mathrm{Na}$, K, bicarbonate, BUN, $\mathrm{Cr}$, daily urine volume, onset of urination, and GFR for both experimental and control groups 48 hours' after intervention were measured and compared. The time of appropriate volume of urine for both groups that was considered at least $0.5 \mathrm{cc} / \mathrm{kg} / \mathrm{h}$ for the patients older than one year and $1 \mathrm{cc} / \mathrm{kg} / \mathrm{h}$ for the patients younger than one-year-old, 48 after intervention, were also measured and compared.

\begin{tabular}{|c|c|c|}
\hline Groups of Study/Sex & No. & Percents \\
\hline \multicolumn{3}{|l|}{ Experimental } \\
\hline Female & 28 & 46.7 \\
\hline Male & 32 & 53.3 \\
\hline \multicolumn{3}{|l|}{ Control } \\
\hline Female & 34 & 56.7 \\
\hline Male & 26 & 43.3 \\
\hline
\end{tabular}

\section{Results}

Measured serum electrolytes ( $\mathrm{Na}$, K and Bicarbonates), BUN (blood urea nitrogen), GFR (glomerular filtration rate), the onset of urination, and the volume of urine of the experimental and control groups were shown in the Table 2. As the statistical analysis in Table 3 implies, the differences of serum creatinine $(\mathrm{P}$ value $=0.022)$ and the time of urine volume improvement $(\mathrm{P}$ value $=0.008$ ) between the experimental and the control groups are significant, however, this difference for the time of the first urination $(\mathrm{P}$ value $=0.906)$ and serum $\mathrm{Na}$ concentration $(\mathrm{P}$ value $=$ 0.233 ), serum $K$ concentration ( $P$ value $=0.339$ ), serum bicarbonate $(\mathrm{P}$ value $=0.712)$, urea concentration $(\mathrm{P}$ value $=$ 0.339 ), and the GFR (P value $=0.119$ ) between the experimental and the control groups are not significant.

In Table 2, in some parameters may have small differences in the number of participants. Those were due to the deletion of some incorrect information and exclusion of them from statistical analysis. These small differences in the number of participants did not affect the results.

\section{Discussion}

AKI which was previously called acute renal failure (ARF), is a clinical manifestation in which the kidneys are unable to preserve the normal homeostasis of water and electrolytes of the body. Acute kidney injury is appeared as oliguria, anuria, or may be exhibited with the normal volume of urine. Oliguria is the most prevalent sign of acute kidney injury. Low dose dopamine ( $1-3 \mu \mathrm{g} / \mathrm{kg} / \mathrm{min})$, due to its effects on dopaminergic receptors of the kidneys, is usually used to dilate the renal arteries and increase the urine output. This study also showed that infusion of 3 $\mu \mathrm{g} / \mathrm{kg} / \mathrm{min}$ of dopamine to improve the serum creatinine and the time of urine volume improvement was significantly effective. Zhang and Harris (5) in a literature review, showed that intrarenal dopaminergic system plays an important role in regulation of the blood pressure. These reviews seem to confirm our findings regarding the effects of low dose dopamine to improve the function of kidneys. Redfors et al. (6) in a clinical trial study, stated that low dose dopamine, by decreasing the renal vascular resistance, increases renal oxygenation without any increase in Na reabsorption. This study also stated that the use of low dose dopamine in AKI patients seems to be helpful. The study of Sulikowska et al. (7) regarding the effectiveness of low dose dopamine to increase the creatinine clearance and the results of the investigation of Protasiewicz et al. (8) which indicated that internal bolus of dopamine is more effective than papaverine to increase the renal blood supply, 


\begin{tabular}{|c|c|c|c|c|}
\hline Group Statistics & $\mathbf{N}$ & Mean & Standard Deviation & Standard Error Mean \\
\hline \multicolumn{5}{|c|}{ Time of first urine excretion } \\
\hline Case & 58 & 15.0517 & 18.18537 & 2.38786 \\
\hline Control & 60 & 14.6667 & 17.09040 & 2.20636 \\
\hline \multicolumn{5}{|c|}{ Urine volume improvement } \\
\hline Case & 55 & 5.1636 & 7.14082 & 0.96287 \\
\hline Control & 60 & 3.7167 & 0.86046 & 0.11109 \\
\hline \multicolumn{5}{|c|}{ Time of urine volume improvement } \\
\hline Case & 52 & 108.0769 & 119.93525 & 16.63203 \\
\hline Control & 60 & 62.0000 & 20.31948 & 2.62323 \\
\hline \multicolumn{5}{|c|}{$\mathrm{Na}^{+}$before intervention } \\
\hline Case & 59 & 141.0881 & 12.89465 & 1.67874 \\
\hline Control & 60 & 137.4417 & 4.42364 & 0.57109 \\
\hline \multicolumn{5}{|c|}{$\mathrm{Na}^{+} 48$ hours after intervention } \\
\hline Case & 59 & 140.8542 & 10.16545 & 1.32343 \\
\hline Control & 60 & 137.9000 & 2.50220 & 0.32303 \\
\hline \multicolumn{5}{|c|}{$\mathrm{K}^{+}$before intervention } \\
\hline Case & 59 & 4.1814 & 0.85354 & 0.11112 \\
\hline Control & 60 & 4.1358 & 0.56711 & 0.07321 \\
\hline \multicolumn{5}{|c|}{$\mathrm{K}^{+} 48$ hours after intervention } \\
\hline Case & 60 & 4.5885 & 4.44834 & 0.57428 \\
\hline Control & 60 & 4.0350 & 0.39950 & 0.05158 \\
\hline \multicolumn{5}{|c|}{$\mathrm{H} \mathrm{CO}_{3}$ before intervention } \\
\hline Case & 60 & 19.6400 & 6.24913 & 0.80676 \\
\hline Control & 60 & 19.7500 & 2.44211 & 0.31527 \\
\hline \multicolumn{5}{|c|}{$\mathrm{H} \mathrm{CO}_{3} 48$ hours after intervention } \\
\hline Case & 60 & 20.8400 & 5.17482 & 0.66807 \\
\hline Control & 60 & 21.1050 & 1.99477 & 0.25752 \\
\hline \multicolumn{5}{|c|}{ BUN before intervention } \\
\hline Case & 59 & 52.3508 & 75.73341 & 9.85965 \\
\hline Control & 60 & 25.3367 & 15.02994 & 1.94036 \\
\hline \multicolumn{5}{|c|}{ BUN 48 hours after intervention } \\
\hline Case & 59 & 44.9627 & 70.91704 & 9.23261 \\
\hline Control & 60 & 19.8167 & 8.67002 & 1.11929 \\
\hline \multicolumn{5}{|c|}{ Cr before intervention } \\
\hline Case & 59 & 2.9083 & 13.27074 & 1.72770 \\
\hline Control & 60 & 0.58005 & 0.47798 & 0.06171 \\
\hline \multicolumn{5}{|c|}{ Cr 48 hours after intervention } \\
\hline Case & 60 & 1.1072 & 1.89457 & 0.24459 \\
\hline Control & 60 & 0.5177 & 0.46434 & 0.05995 \\
\hline \multicolumn{5}{|c|}{ GFR before intervention } \\
\hline Case & 59 & 61.0934 & 43.28708 & 5.63550 \\
\hline Control & 60 & 74.1710 & 20.99378 & 2.71029 \\
\hline \multicolumn{5}{|c|}{ GFR 48 hours after intervention } \\
\hline Case & 60 & 64.9588 & 47.87109 & 6.18013 \\
\hline Control & 60 & 83.5378 & 20.91299 & 2.69986 \\
\hline
\end{tabular}

${ }^{\mathrm{a}} \mathrm{H}_{0}: \mu_{1}=\mu_{2}, \mathrm{H}_{1}: \mu_{1} \neq \mu_{2}$.

confirm the findings of this study, which showed the effectiveness of low dose dopamine to correct the time of urine volume and improve the serum creatinine concentration. The study of Lauschke et al. (9) concerning the effects of low dose dopamine on the patients with acute renal injury and the patients without AKI, showed that dopamine in patients more than 55 years old increases the vascular resis- tance and worsens renal perfusion, on the contrary in children causes renal vascular relaxation and improve renal perfusion. Since our study at the Arak pediatrics hospital was focused on the children, the findings of Lauschke et al. also confirms the results of our study, which stated that in children, low dose dopamine is effective to improve their renal function. 
Table 3. Compares the Analytical Results and Co-variance Analysis in Experimental and Control Groups

\begin{tabular}{|c|c|}
\hline Variants & Levels of Significant \\
\hline Time of first urine excretion & 0.906 \\
\hline Urine volume improvement & 0.141 \\
\hline Time of urine volume improvement & 0.008 \\
\hline $\mathrm{Na}^{+}$after 48 hours $^{\mathrm{a}}$ & 0.233 \\
\hline $\mathrm{K}^{+}$after 48 hours & 0.339 \\
\hline $\mathrm{H} \mathrm{CO}_{3}$ after 48 hours & 0.712 \\
\hline BUN after 48 hours ${ }^{a}$ & 0.339 \\
\hline Cr after 48 hours & 0.022 \\
\hline GFR after 48 hours $^{\mathrm{a}}$ & 0.119 \\
\hline
\end{tabular}

${ }^{\mathrm{a}}$ ANCOVA.

\subsection{Conclusion}

This study showed that use of low dose dopamine (3 $\mu \mathrm{g} / \mathrm{kg} / \mathrm{min}$ ) IV infusion in children improves the required time for urine volume correction and the serum creatinine concentration.

\section{Acknowledgments}

The authors gratefully acknowledge the Research Council of Arak University of Medical Sciences for their financial support. This work was performed in partial fulfillment of the requirements for the degree of Pediatrics Medicine of Vahab Ghanbari Sheldareh, in the School of Medicine, Arak University of Medical Sciences, Arak, Iran.

\section{Footnotes}

Authors' Contribution: Study concept and design: Parsa Yousefichaijan, Vahab Ghanbari Sheldareh, Yazdan Ghandi; analysis and interpretation of data: Vahab Ghanbari Sheldareh, Parsa Yousefichaijan, Yazdan Ghandi; drafting of the manuscript: Vahab Ghanbari Sheldareh; critical revision of the manuscript for important intellectual content: Vahab Ghanbari Sheldareh, Parsa Yousefichaijan, Yazdan Ghandi; statistical analysis: Danial Habibi.

Conflict of Interests: No conflict.

Ethical Considerations: IR.ARAKMU.REC.1395.222.

Funding/Support: None declared.

\section{References}

1. Ali MA, Rehman A, Ahmed E. Association of in-hospital outcome of Acute Kidney Injury (AKI) with etiology among newborns at a tertiary care unit. PakJ Med Sci. 2018;34(1):125-9. doi: 10.12669/pjms.341.13955. [PubMed: 29643892]. [PubMed Central: PMC5856996].

2. Yuan SM. Acute kidney injury after pediatric cardiac surgery. Pediatr Neonatol.2018. doi:10.1016/j.pedneo.2018.03.007.[PubMed:29891225].

3. Schreuder MF, Bokenkamp A, van Wijk JAE. Interpretation of the Fractional Excretion of Sodium in the Absence of Acute Kidney Injury: A Cross-Sectional Study. Nephron. 2017;136(3):221-5. doi: 10.1159/000468547. [PubMed: 28391266]. [PubMed Central: PMC5516416]

4. Kliegman RM, Bonita F S, Joseph W St GIII, Nina F S. Nelson textbook of pediatrics. 20th ed. Elsevier Saunders; 2015. p. 2539-43.

5. Zhang MZ, Harris RC. Antihypertensive mechanisms of intra-renal dopamine. Curr Opin Nephrol Hypertens. 2015;24(2):117-22. doi 10.1097/MNH.0000000000000104. [PubMed: 25594544]. [PubMed Central: PMC4651846].

6. Redfors B, Bragadottir G, Sellgren J, Sward K, Ricksten SE. Dopamine increases renal oxygenation: A clinical study in post-cardiac surgery patients. Acta Anaesthesiol Scand. 2010;54(2):183-90. doi: 10.1111/j.13996576.2009.02121.x. [PubMed: 19764906].

7. Sulikowska B, Johnson RJ, Wiechecka-Korenkiewicz J, Korenkiewicz J, Marszalek A, Odrowaz-Sypniewska G, et al. Dopamine-induced changes in serum erythropoietin and creatinine clearance reflect risk factors for progression of IgA nephropathy. J Investig Med. 2015;63(6):811-5. doi: 10.1097/JIM.0000000000000214. [PubMed: 26107422].

8. Protasiewicz M, Poczatek K, Poreba R, Derkacz A, Podgorski M, Goslawska K, et al. Comparison of the renal hyperemic effects of papaverine and dopamine in patients with renal artery stenosis. J Am Soc Hypertens. 2015;9(1):9-14. doi: 10.1016/j.jash.2014.10.004. [PubMed: 25533109].

9. Lauschke A, Teichgraber UK, Frei U, Eckardt KU. 'Low-dose' dopamine worsens renal perfusion in patients with acute renal failure. Kidney Int. 2006;69(9):1669-74. doi: 10.1038/sj.ki.5000310. [PubMed: 16572117]. 